\title{
ANALISIS DAN PERANCANGAN SITEM INFORMASI PENJAMINAN MUTU STANDAR PENDIDIKAN DAN PENGAJARAN PADA STMIK DCI TASIKMALAYA
}

\author{
Sarmidi $^{1}$, Sutarman ${ }^{2}$ \\ ${ }^{1}$ STMIK DCI Tasikmalaya, ${ }^{2}$ STMIK Triguna Tangerang \\ ${ }^{1}$ Jl. Sutisna Senjaya No.158-A Tasikmalaya, ${ }^{2}$ Komplek Mahkota Mas Blok E 30 Tangerang
}

\begin{abstract}
The quality assurance system at STMIK DCI Tasikmalaya is now started with the determination of policies, standards, manuals, and form documents. Only in the implementation is not supported by information systems, so the process of socialization of policies, standards, manuals, and is not effective and may result in limited access for the parties in need. In addition, in the implementation of monitoring and evaluation (Monev) the standard documents of education and teaching also became less efficient and can hamper the implementation of internal quality assurance system. To that end, then created a prototype web-based quality assurance information system for STMIK DCI Tasikmalaya and modeled it using UML. With the prototype of quality assurance information system is expected to assist the implementation of quality assurance system for the STI Tasikmalaya DCI to improve the quality of the institution.
\end{abstract}

Keywords: Design, Quality assurance system, education and teaching,

\begin{abstract}
Abstrak
Sistem penjaminan mutu di STMIK DCI Tasikmalaya saat ini sudah dimulai dengan penetapan kebijakan, standar, manual,serta dokumen formulir. Hanya saja dalam pelaksanaanya tidak didukung oleh sistem informasi, sehingga proses sosialisasi kebijakan, standar, manual, dan tersebut belum efektif dan dapat mengakibatkan adanya keterbatasan akses bagi pihak-pihak yang membutuhkan. Selain itu dalam pelaksanaan monitoring dan evaluasi (Monev) dokumen standar pendidikan dan pengajaran juga menjadikurang efisien dan dapat menghambat pelaksanaan sistem penjaminan mutu internal.Untuk itu, maka dibuatlah suatu prototipe sistem informasi penjaminan mutu berbasis web untuk STMIK DCI Tasikmalaya dan memodelkannya dengan menggunakan UML.Dengan adanya prototipe sistem informasi penjaminan mutu ini diharapkan dapat membantu pelaksanaan sistem penjaminan mutu bagi pihak STMIK DCI Tasikmalaya guna peningkatan kualitas institusi.
\end{abstract}

Kata-kunci : Perancangan, Sistem penjaminan mutu, pendidikan dan pengajaran, 


\section{PENDAHULUAN}

Dalam beberapa tahun terakhir, sistem penjaminan mutu perguruan tinggi (SPM-PT) menjadi hal yang sangat penting dalam menunjang keberhasilan dan mutu perguruan tinggi tersebut agar menjadi sehat (lebih baik). Sejak Direktorat Jenderal Pendidikan Tinggi mencanangkan posisi strategis penjaminan mutu (quality assurance) di dalam Higher Education Long Term Strategy (HELTS) 2003 - 2004, maka kegiatan penjaminan mutu telah berkembang sedemikian rupa di masing-masing perguruan tinggi. Untuk melaksanakan SPM-PT perlu bertahap sesuai dengan kesiapan perguruan tinggi, namun sebaiknya disusun dengan efektif.

Pelaksanaan SPM-PT pada umumnya dimulai dari kegiatan pendidikan, dilanjutkan pada bidang penelitian kemudian pengabdian kepada masyarakat, dengan demikian dapat mencakup seluruh kegiatan akademik. Setelah mampu melaksanakan SPM-PT di bidang akademik, kemudian dapat dikembangkan ke bidang yang lebih luas, misalnya keuangan, sumberdaya manusia dan seterusnya. Tujuan akhir adalah SPM-PT untuk menjamin dan meningkatkan mutu seluruh bidang yang terkait dengan pengelolaan perguruan tinggi sehingga tercipta perguruan tinggi yang sehat dan baik.

Penjaminan Mutu Perguruan Tinggi merupakan konsep multi Stakeholders; masyarakat luas sekitar, Nasional, Dunia, Kemenristek Dikti, dan Ban PT. Sistem penjaminan mutu internal di perguruan tinggi dilakukan atas dasar penjaminan mutu internal, penjaminan mutu eksternal, dan proses akreditasi baik program studi maupun institusi. Sehubungan dengan konsep penjaminan mutu tersebut, maka secara langsung maupun tidak langsung berhubungan dengan input dan output yang dihasilkan dari suatu perguruan tinggi, sehingga menghasilkan alumni yang memiliki mutu sesuai dengan harapan para stakeholder.

STMIK DCI Tasikmalaya merupakan suatu perguruan tinggi bidang ilmu komputer yang telah berdiri sejak tahun 1999. STMIK DCI Tasikmalaya memiliki visi "Pada Tahun 2020 akan menjadi Perguruan Tinggi yang unggul dan elegan dalam melaksanakan Tridharma Perguruan Tinggi dengan tingkat akreditasi A untuk program studi dan institusi”. Untuk mewujudkan visi tersebut kini STMIK DCI Tasikmalaya telah mempuyai Lembaga Penjaminan Mutu yang ada sejak tahun 2016.

Sehubungan dengan konsep sistem penjaminan mutu yang telah dikemukakan di atas maka hal tersebut merupakan modal kepercayaan yang harus dibangun oleh STMIK DCI Tasikmalaya. Untuk mendapatkan kepercayaan akan mutu tersebut perlu adanya sebuah sistem penjaminan mutu yang baik dan didukung oleh teknologi informasi yang baik pula.

Berdasarkan pengamatan yang telah dilakukan, saat ini pelaksanaan sistem penjaminan mutu internal di STMIK DCI Tasikmalaya sudah mulai dilaksanakan dengan menetapkan dokumen kebijakan, dokumen standar, dokumen manual mutu dan kebijakan mutu, tahapan berikutnya akan dilanjutkan dengan realisasi dan evaluasi dari sistem penjaminan mutu tersebut. Hanya saja pada saat ini sistem penjaminan mutu tersebut masih dilakukan secara manual seperti prosedur dan kebijakan yang ada di arsipkan secara manual, disosialisasikan hanya melalui rapat sehingga adanya keterbatasan akses bagi pihak-pihak yang membutuhkan. Selain itu monitoring dan evaluasi proses pendidikan dan pengajaran juga dilakukan secara manual sehingga membutuhkan waktu yang cukup lama untuk mendapatkan hasilnya. Oleh karena itu maka dibutuhkan dukungan sistem informasi yang dapat mengakomodasi semua kebutuhan dari sistem penjaminan mutu.

Berdasarkan masalah di atas maka penelitian ini mengusulkan sebuah perancangan sistem informasi penjaminan mutu pada STMIK DCI Tasikmalaya yang selaras dengan kebutuhan dari sistem penjaminan mutu tersebut.

PERUMUSAN MASALAH

Berdasarkan latar belakang tersebut maka dapat dirumuskan pokok permasalahan yang akan dibahas dalam penelitian ini, yaitu:

1. Bagaimana menganalisis dan merancang sistem informasi penjaminan mutu berbasis web untuk

2. Bagaimana STMIK DCI Tasikmalaya? membangun prototipe sistem informasi penjaminan mutu berbasis web 
untuk

STMIK DCI Tasikmalaya dan memodelkannya dengan menggunakan

UML?

\section{BATASAN MASALAH}

Adapun batasan masalah yang dapat membantu dalam penyusunan penelitian ini agar tidak menyimpang dari maksud dan tujuan yang ingin dicapai adalah sebagai berikut:

1. Penelitian ini hanya dibatasi pada analisis dan perancangan untuk membangun sistem informasi penjaminan mutu pendidikan yang berfokus pada standar pendidikan dan pengajaran di STMIK DCI Tasikmalaya.

2. Penelitian ini hanya dibatasi pada penyajian rumusan 8 (delapan) standar pendidkan dan pengajaran, tidak termasuk penelitian dan pengabdian masyarakat.

3. Perancangan sistem informasi penjaminan mutu untuk STMIK DCI Tasikmalaya hanya sebatas prototipe sistem berbasis web.

4. Perancangan sistem informasi penjaminan mutu untuk STMIK DCI Tasikmalaya menggunakan metode berorientasi objek dengan tools UML.

\section{TUJUAN PENELITIAN}

Tujuan dari penelitian ini adalah sebagai berikut:

1. Menganalisa dan merancang sistem informasi penjaminan mutu berbasis web untuk STMIK DCI Tasikmalaya.

2. Membangun Prototipe sistem informasi penjaminan mutu berbasis web untuk STMIK DCI Tasikmalaya dengan menggunakan metode berorientasi objek dengan tools UML.

\section{MANFAAT PENELITIAN}

Manfaat dari penelitian ini adalah sebagai berikut:

1. Dengan adanya sistem informasi penjaminan mutu ini diharapkan dapat membantu Lembaga Sistem Penjaminan Mutu Internal (SPMI dalam mengembangkan budaya mutu di lingkungan STMIK DCI Tasikmalaya sesuai dengan visi dan misinya.

2. Dengan adanya sistem informasi penjaminan mutu ini diharapkan dapat mempermudah pihakpihak terkait khususnya SPMI dalam melaksanakan monitoring dan evaluasi (Monev) pada dokumen standar pendidikan dan pengajaran yang merupakan salah satu dari Tridharma Perguruan Tinggi.

3. Sistem informasi penjaminan mutu ini diharapkan dapat mempermudah lembaga sistem penjaminan mutu internal STMIK DCI dalam melaksanakan tugas penjaminan mutunya dengan menyediakan berbagai informasi yang dibutuhkan.

\section{METODOLOGI PENILITIAN}

Kerangka kerja penelitian menggambarkan tahapan proses yang dilakukan dalam penelitian agar penelitian dapat berjalan dengan baik dan tujuan yang telah ditetapkan dapat tercapai. Pada penelitian ini penulis menggunakan tahapan kerangka kerja penelitian sebagai berikut :

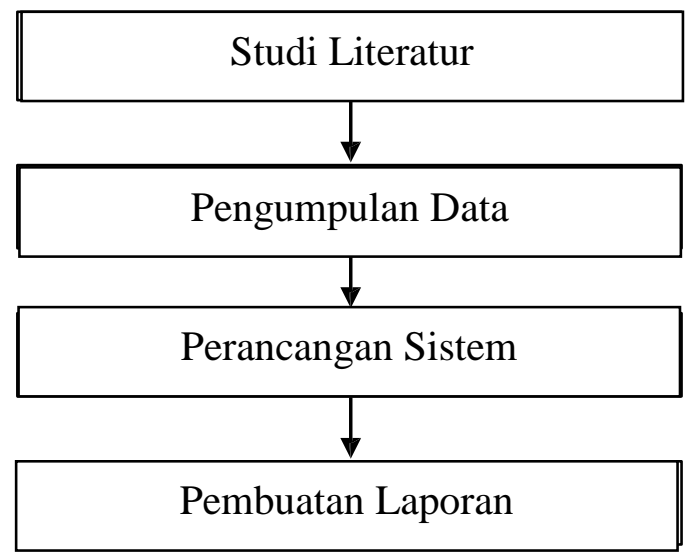

Gambar1. Kerangka Kerja Penelitian 


\section{Konsep Mutu}

\section{HASIL DAN PEMBAHASAN}

Mutu merupakan sesuatu yang tidak mutlak tetapi lebih kepada apa yang dapat diterima dari sisi pelanggan, hanya saja mutu tidak hanya berdasarkan atas apa yang dibutuhkan oleh pelanggan tetapi juga berdasarkan atas apa yang pelanggan harapkan. Hal inilah yang membuat pemenuhan atas mutu sangat sulit karena hanya sedikit dari kita yang mengetahui apa yang sebenarnya kita inginkan. (Jay Schlickman, 2003:19).

Menurut ISO 9000:2000 dalam buku Hoyle (2007:10) Mutu adalah kemampuan serangkaian karakteristik yang dimiliki produk untuk memenuhi persyaratan/kebutuhan.

\section{Dimensi Mutu}

Menurut Garvin dalam buku Mishra (2007:24) terdapat 8 dimensi mutu yaitu:

1. Performance : kinerja karakteristik utama produk

2. Feature : ciri khas

3. Reliability : keterandalan, konsistensi kinerja pada periode waktu tertentu

4. Conformance : kesesuaian dengan spesifikasi

5. Durability : umur produk

6. Serviceability $\quad$ : kemudahan untuk diperbaiki

7. Aesthetic : estetika

8. Perceived quality : reputasi (ukuran tidak langsung karena informasi produk tidak lengkap)

\section{Sistem Penjaminan Mutu Perguruan Tinggi (SPM-PT)}

Berdasarkan Permendiknas nomor 63 tahun 2009 penjaminan mutu pendidikan adalah suatu kegiatan sistematik dan terpadu oleh satuan atau program pendidikan, penyelenggaraan satuan atau program pendidikan, pemerintah daerah pemerintah dan masyarakat untuk menaikkan tingkat kecerdasan kehidupan bangsa melalui pendidikan.

Secara umum dapat dikemukakan bawa penjaminan mutu merupakan perencanaan, penerapan, pengendalian dan pengembangan standar mutu perguruan tinggi secara konsisten dan berkelanjutan, sehingga stakeholders, baik internal maupun eksternal memperoleh kepuasan.

SPM-PT merupakan sistem penjaminan mutu penyelenggaraan pendidikan tinggi melalui 3 sub sitem yang masing-masing merupakan sistem pula, yaitu:

a. Pangkalan Data Perguruan Tinggi (PDPT) Nasional

PDPT Nasional merupakan kegiatan sistematik pengumpulan, pengolahan, dan penyimpanan data serta informasi tentang penyelenggaraan pendidikan tinggi di semua perguruan tinggi oleh Ditjen Dikti, untuk mengawasi penyelenggaraan pendidikan tinggi oleh pemerintah.

b. Sistem Penjaminan Mutu Internal (SPMI)

SPMI merupakan kegiatan sistematik penjaminan mutu pendidikan tinggi di perguruan tinggi oleh perguruan tinggi untuk mengawasi penyelenggaraan pendidikan tinggi oleh perguruan tinggi secara berkelanjutan (continuous improvement)

c. Sistem Penjaminan Mutu Eksternal (SPME)

SPME merupakan kegiatan sistemik penilaian kelayakan program dan/atau perguruan tinggi

oleh BAN-PT atau lembaga mandiri di luar perguruan tinggi untuk dan atas nama masyarakat, sebagai bentuk akuntabilitas publik.

\section{Sistem Penjaminan Mutu Internal (SPMI)}

Sistem penjaminan mutu internal di suatu perguruan tinggi merupakan kegiatan mendiri dari perguruan tinggi yang bersangkutan sehingga proses tersebut dirancang, dijalankan, dan dikendalikan sendiri oleh perguruan tinggi yang bersangkutan tanpa campur tangan dari pemerintah, dalam hal ini Kemenristekdikti.

Tujuan dari SPMI adalah memelihara dan meningkatkan mutu pendidikan tinggi secara berkelanjutan, yang dijalankan oleh suatu perguruan tinggi secara internal, untuk mewujudkan visi, serta untuk memenuhi kebutuhan stakeholders melalui penyelenggaraan Tridharma Perguruan Tinggi.

Agar perguruan tinggi senantiasa mampu memenuhi tujuannya, maka ada beberapa unsur 
yang terdapat dalam SPMI yang dimuat dalam satu naskahdokumen/buku, yakni:

1. Naskah/dokumen/buku kebijakan, berisi tentang definisi, konsep, tujuan, strategi, jenis standar, prioritas SPMI

2. Naskah/dokumen/buku manual, berisi tentang mekanisme penetapan, pelaksanaan, evaluasi pelaksanaan, pengendalian pelaksanaan, dan peningkatan yang dikenal dengan model PPEPP untuk kepentingan stakeholders yang menjalankan mekanisme tersebut dalam SPMI

3. Naskah/dokumen/buku standar, berisi tentang rumusan substansi atau isi setiap standar yang digunakan dalam SPMI perguruan tinggi yang bersangkutan, termasuk delapan standar minimal dari Standar Nasional Pendidikan dan Pengajaran, yaitu:

\begin{tabular}{|c|l|l|}
\hline No. & $\begin{array}{l}\text { STANDAR NASIONAL PT } \\
\text { (TRIDARMA PT) }\end{array}$ & \multicolumn{1}{|c|}{ RUANG LINGKUP } \\
\hline 1 & $\begin{array}{l}\text { Standar Nasional } \\
\text { Pendidikan dan Pengajaran }\end{array}$ & $\begin{array}{l}\text { a. standar kompetensi lulusan; } \\
\text { b. standar isi pembelajaran; } \\
\text { c. standar proses pembelajaran; } \\
\text { d. standar penilaian pembelajaran; } \\
\text { e. standar dosen dan tenaga kependidikan; } \\
\text { f. standar sarana dan prasarana } \\
\text { pembelajaran; } \\
\text { g. standar pengelolaan pembelajaran } \\
\text { h. standar pembiayaan pembelajaran }\end{array}$ \\
\hline
\end{tabular}

\section{Analisa dan Perancangan Berorientasi Objek}

Tujuan dari analisa berorientasi objek adalah untuk mengembangkan sebuah model yang menggambarkan suatu perangkat lunak komputer yang dapat bekerja untuk memenuhi seperangkat persyaratan yang ditentukan oleh pengguna. Dalam membangun sebuah model analisis sama halnya seperti metode analisis konvensional, yakni membangun sebuah model analisis yang menggambarkan informasi, fungsi, dan perilaku objek. (Pressman, 2001; 572)

\section{UML (Unified Modelling Language)}

UML dinotasikan sebagai diagram untuk menggambarkan atau memvisualisalikan, menentukan, membangun dan mendokumentasikan aplikasi perangkat lunak. [Barclay \& Savage,2004;3]. Use case adalah teknik untuk merekam persyaratan fungsional sebuah sistem. Use case mendeskripsikan interaksi tipikal antara pada pengguna sistem dengan sistem. Setiap use case memiliki aktor utama yang meminta sistem untuk memberi sebuah layanan. Aktor utama adalah aktor dengan tujuan yang akan dipenuhi oleh use case dan biasanya adalah inisiator use case. Selain itu terdapat banyak aktor lain yang berkomunikasi dengan sistem pada saat menjalankan use case (aktor sekunder).

\section{PROTOTIPE (PROTOTYPE)}

Prototipe adalah suatu proses dalam membangun sebuah model yang menunjukkan fitur dari produk yang diusulkan, layanan atau sistem. Dalam membangun sebuah model yang sesuai dengan kebutuhan dasar bisnis, maka prototipe memungkinkan pengguna untuk melihat, bekerja dengan, dan mengevaluasi model dengan menyarankan perubahan pada model yang meningkatkan kemungkinan sebuah keberhasilan dari sistem yang diusulkan (Haag \& Cummings,2008;211).

\section{DIAGRAM USE CASE}

Use case diagram digunakan untuk memodelkan fungsional system yang digunakan serta menggambarkan kebutuhan system dari sudut pandang user. Berdasarkan asumsi yang digunakan dapat digambarkan diagram use case Sistem Informasi Penjaminan Mutu sebagai berikut 


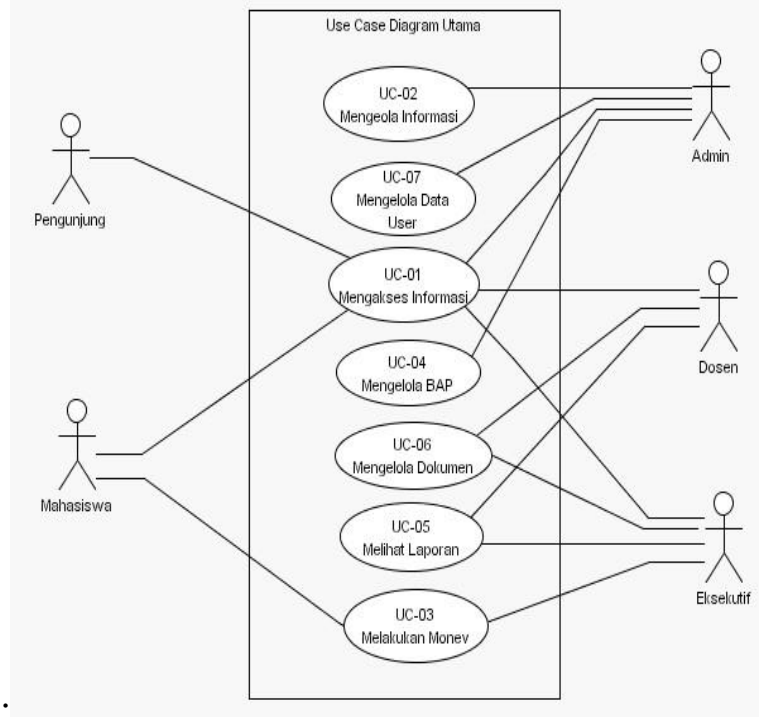

Gambar 2. Diagram Use Case Sistem Informasi Penjaminan Mutu

Berdasarkan use case diagram sistem informasi penjaminan mutu, maka use case melakukan monitoring dan evaluasi dapat diuraikan lebih terperinci sebagai berikut :

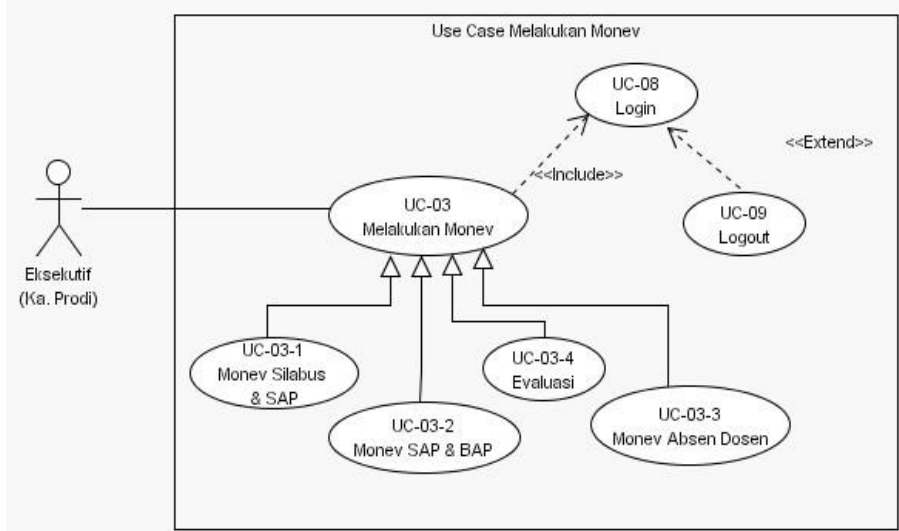

\section{Gambar 3. Diagram Use Case Melakukan Monitoring dan Evaluasi}

Berdasarkan gambar diatas, maka dapat diuraikan lebih rinci lagi mengenai use case diagram evauasi sebagai berikut :

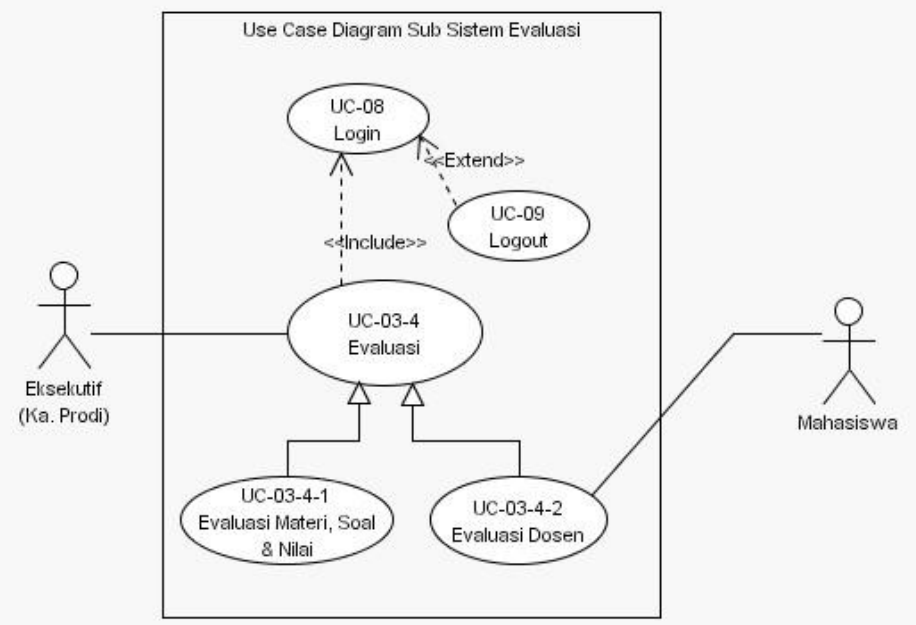

Gambar 4 Diagram Use Case Evaluasi 
DIAGRAM CLASS

Class diagram merupakan suatu model statis yang menunjukkan class-class dan hubungan diantaranya dan senantiasa konstant didalam sistem sepanjang waktu. Diagram class menggambarkan class berikut perilaku dan keadaan dengan menghubungkannya antar classclass. Berdasarkan deskripsi diagram class dapat digambarkan sbb :

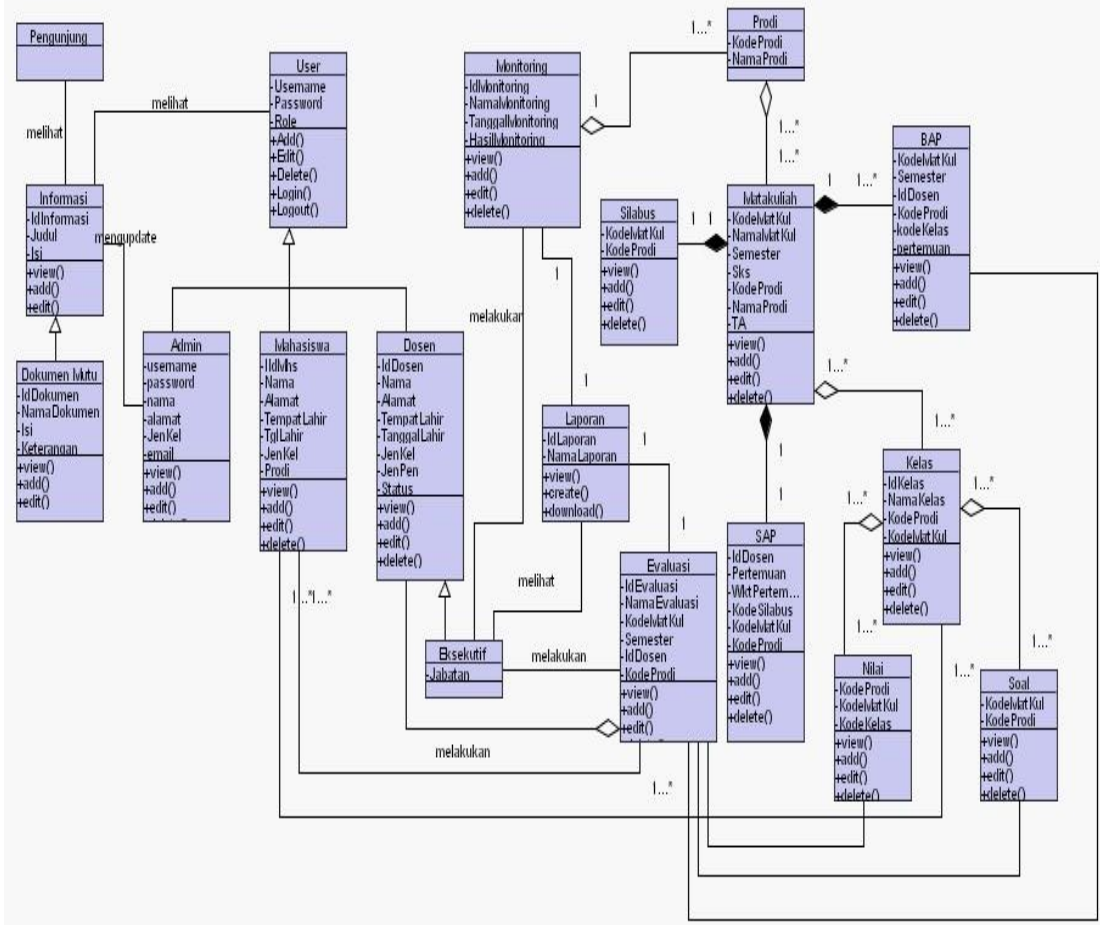

\section{Gambar 6. Diagram Class Sistem Informasi Penjaminan Mutu}

Diagram Activity Evaluasi Standar Pendidikan dan Pengajaran

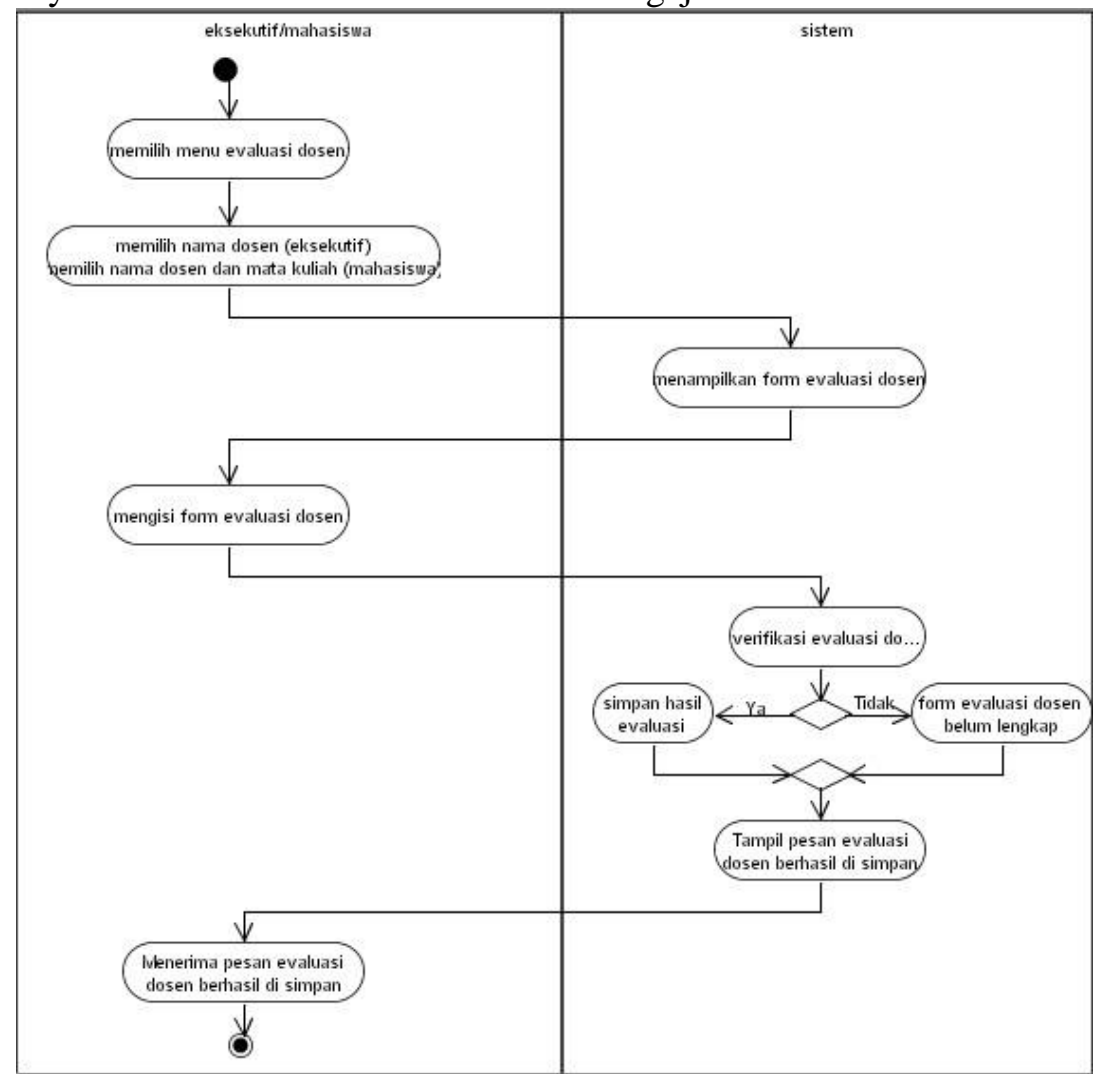




\section{Gambar 5 Diagram Activity Evaluasi Standar Pendidikan dan Pengajaran}

\section{PERANCANGAN PROTOTIPE SISTEM}

Prototipe adalah suatu versi sistem potensial yang disediakan bagi pengembang dan calon pengguna yang dapat memberikan gambaran bagaimana kira-kira sistem tersebut akan berfungsi bila telah disusun dalam bentuk yang lengkap. Prototipe bertujuan untuk memperoleh umpan balik dari pengguna yang akan memungkinkan prototipe di ulang beberapa kali sehingga menghasilkan prototipe yang dianggap sempurna. Adapun prototipe dari sistem informasi penjaminan mutu STMIK DCI Tasikmalaya adalah sebagai berikut:

$\begin{array}{llll}\text { STMIK DCl Home - Profle - Dokumen - Berita - Tentang - } & \text { Copyright } \Theta 2017\end{array}$

SELAMAT DATANG PADA SISTEM PEN JAMINAN MUTU INTERNAL - SPMI STMIK DCI

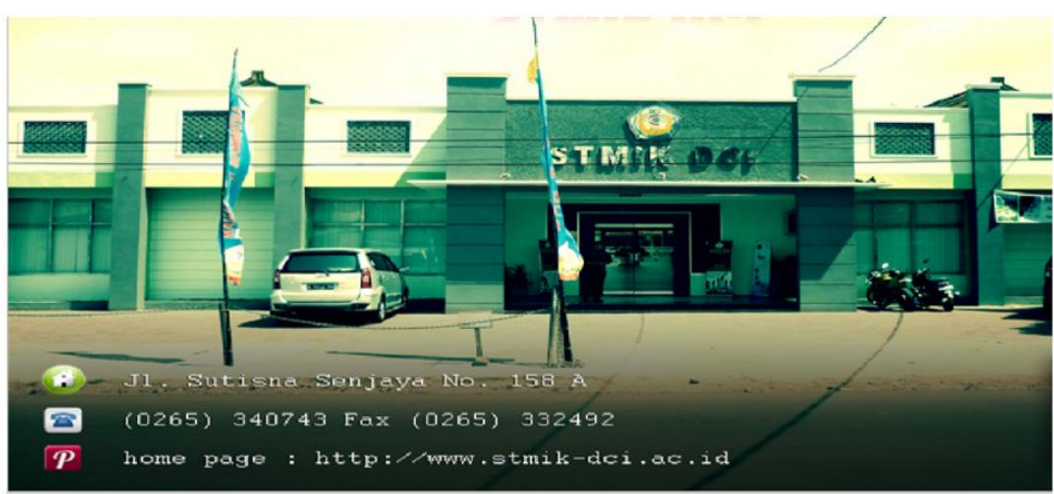

SEKOLAH TINGGI MANAJEMEN INFORMATIKA DAN KOMPUTER - STMIK DCI

Gambar 7. Gedung Utama

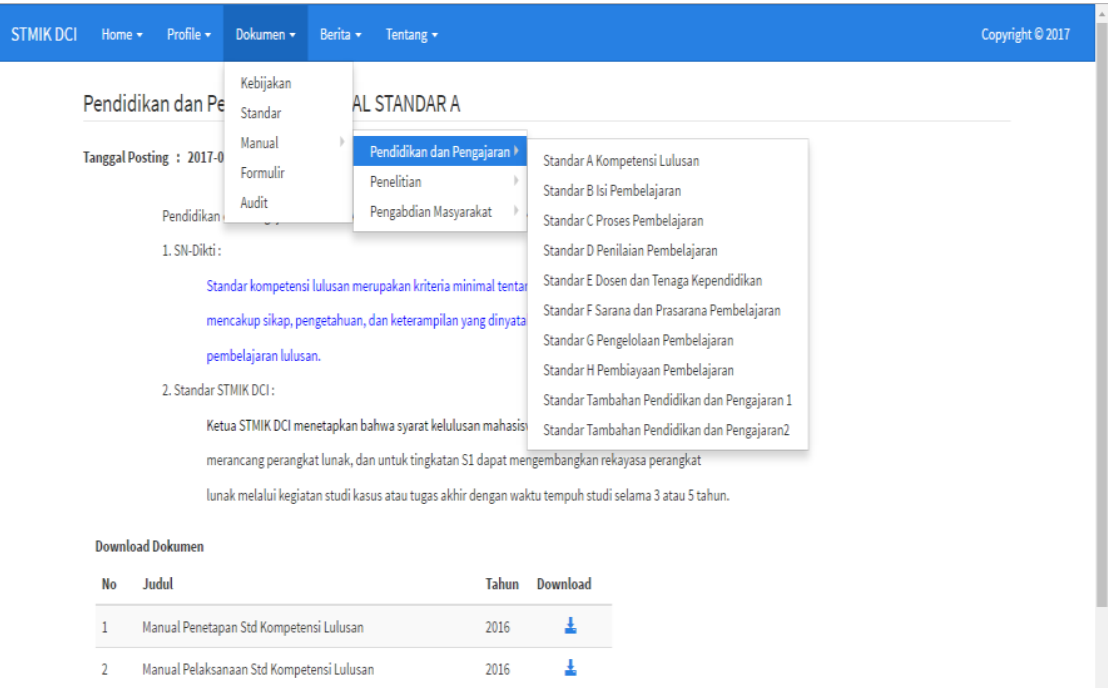

G a m b a r 8. Evaluasi Standar Pendididikan dan Pengajaran pada Jurusan 


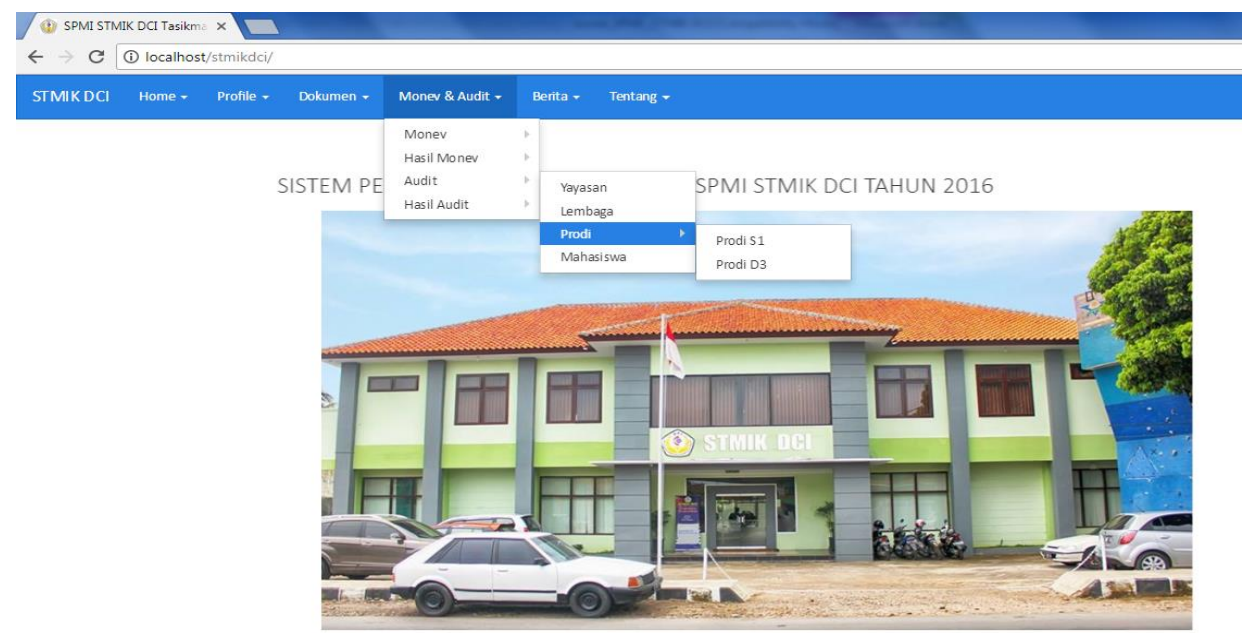

Gambar 9. Gedung Pendidikan dan Pengajaran

\section{KESIMPULAN}

Dari perancangan sistem informasi pada LPMP STMIK DCI Tasikmalaya Jambi maka dapat ditarik kesimpulan sebagai berikut:

1. Sistem penjaminan mutu di STMIK DCI saat ini baru sebatas pada penetapan standar pada bidang pendidikan dan pengajaran saja. Proses sosialisasi hanya melalui rapat saja sehingga adanya keterbatasan akses bagi pihak- pihak yang membutuhkan, karena itu dibutuhkan sebuah rancangan sistem informasi berbasis web yang dapat membantu STMIK DCI Tasikmalaya dalam menjalankan sistem penjaminan mutu tersebut.

2. Penelitian ini menghasilkan sebuah prototipe sistem informasi penjaminan mutu STMIK DCI Tasikmalaya berbasis web yang dapat diimplementasikan lebih lanjut sehingga dapat membantu pelaksanaan sistem penjaminan mutu di STMIK DCI Tasikmalaya Jambi.

3. Prototipe sistem informasi penjaminan mutu ini menyediakan layanan-layanan yang berupa pengelolaan dokumen penunjang monitoring dan evaluasi (Monev) semua standar dalam pendidikan dan pengajaran yang secara otomasis sistem dapat menghitung seluruh hasil Monev yang telah dilakukan. Sehingga memudahkan pihak eksekutif dalam melakukan monitoring dan evaluasi (Monev) perkuliahan guna meningkatkan kualitas perkuliahan.

\section{SARAN}

Berdasarkan penelitian yang telah dilakukan maka dapat dikemukakan saran-saran sebagai berikut :

1. Prototipe ini belum memperhatikan masalah keamanan data (security), maka untuk penelitian lebih lanjut dapat dilengkapi dengan sistem keamanan data.

2. Penelitian ini dapat dijadikan referensi untuk penelitian selanjutnya yang merupakan implementasi dari penelitian ini sehingga dapat membantu pihak STMIK DCI dalam menjalankan sistem penjaminan mutu yang berkelanjutan guna peningkatan kualitas institusi.

3. Sistem informasi penjaminan mutu ini akan lebih maksimal apabila dalam penerapannya nanti terintegrasi pada sistem informasi yang lain baik akademik maupun non akademik terutama sistem informasi akademik STMIK DCI Tasikmalaya.

\section{DAFTAR PUSTAKA}

[1]. Buku Panduan Sistem Penjaminan Mutu Perguruan Tinggi (SPM-PT). Dirjen Dikti. 2010

[2]. Buku Panduan Pelaksanaan Sistem Penjaminan Mutu Perguruan Tinggi (SPM-PT) Bidang Akademik. Dirjen Dikti. 2006

[3]. Buku Pedoman Akademik STMIK DCI Tasikmalaya TA.2016/2017. STMIK DCI Tasikmalaya. 2016 
[4]. Barclay, K \& Savage, J. 2004. Object-Oriented Design with UML and Java. United States of America : Elseiver.

[5]. C. Laudon, Kenneth; \& P. Laudon, Jane. 2010. Management Information Systems :Managing The Digital Firm. Eleventh Edition.New Jersey, United States of America : Pearson Prentice Hall.

[6]. Dennis, Alan; Wixom, Haley Barbara: \&Tegarden, David. 2005. Systems Analysis and Design with UML Version 2.0 : An Object-Oriented Approach.Second Edition. United States of America : John Wiley \& Sons, Inc.

[7]. Dennis, Alan; Wixom, Haley Barbara: \&Tegarden, David. 2010. Systems Analysis and Design with UML An Object-Oriented Approach.Second Edition. United States of America: John Wiley \& Sons, Inc.

[8].El-Bakry, Hazem M. Proceeding of The 8th WSEAS International Conference on Education and Aducational Technology: Design of Quality Assurance Management System for E- Universities

[9]. Fowler, Martin., 2005, UML Distilled Edisi 3.Yogyakarta :Andi

[10]. Haag, Stephen; \& Cummings, Meave. 2008. Information Systems

[11]. Essentials. Second Edition. New York : McGraw-Hill.

[12]. Hoyle, David. 2001. ISO 9000 Quality System Handbook. Fourth Edition. United States of America :Elsever.

[13]. Hoyle, David. 2007. Quality Management Essentials. United States of America : Elsever.

[14]. McLeod, Jr. Raymond; \& P. Schell, George. 2007. Management Information Systems. Tenth edition. New Jersey, United States of America : Pearson Prentice Hall

[15]. Whitten, L. Jeffery; Bentley, D. Lonnie; \&Dittman, C. Kevin. 2004. Systems Analysis \& Design Methods. Sixth Edition. New York, United States of America: The McGraw Hill Companies, Inc. 